\title{
Gait Kinematic Parameters in Healthy and Rheumatoid Arthritis Postmenopausal Women
}

\author{
Pedro Aleixo ${ }^{1 *}$, José Vaz Patto ${ }^{2,}$ Helena Moreira ${ }^{3}$ and João Abrantes ${ }^{1}$ \\ ${ }^{1}$ MovLab/Universidade Lusófona de Humanidades e Tecnologias, Portugal \\ ${ }^{2}$ Instituto Português de Reumatologia, Portugal \\ ${ }^{3}$ Universidade de Trás-os-Montes e Alto Douro, Portugal
}

*Corresponding author: Pedro Aleixo, MovLab/Universidade Lusófona de Humanidades e Tecnologias Av. do Campo Grande, Lisboa, Portugal

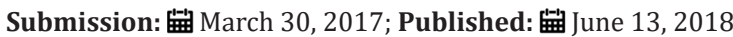

\begin{abstract}
The aim of the study was to compare rheumatoid arthritis (RA) postmenopausal women and age-matched healthy postmenopausal women (AHPW) in regard to functional capacity, gait kinematic and temporal parameters, and its intra-individual variability. 20RA postmenopausal women and 20AHPW were selected. A three-dimensional motion analysis system (9 cameras) were used to collect gait kinematic parameters (200Hz), synchronized with a force plate $(1000 \mathrm{~Hz})$. Data were analysed by a biomechanical model based on mechanical segments and joint centres, which combined anthropometric measurements and the placement of 41 spherical reflective markers on subjects anatomical landmarks. Subjects walked barefoot at a comfortable speed and performed 14 valid trials (7 left and 7 right foot-steps on force plate). Health Assessment Questionnaire (HAQ) was used to assess functional capacity. Independent-samples t-test was used. RA postmenopausal women yielded: lower gait speed ( $<<0.001)$; lower centre of mass antero-posterior velocity $(p<0.001)$; lower cadence $(p<0.001)$; lower stride length $(p<0.001)$; lower heel antero-posterior velocity at heel strike ( $p<0.05)$. RA postmenopausal women also yielded a higher intra-individual coefficient of variation in regard to gait speed ( $<<0.01)$, centre of mass antero-posterior velocity $(\mathrm{p}<0.05)$, cadence $(\mathrm{p}<0.01)$, stride length $(\mathrm{p}<0.05)$, and heel antero-posterior velocity at heel strike $(\mathrm{p}<0.01)$. A higher $\mathrm{HAQ}$ score was observed in RA postmenopausal women $(\mathrm{p}<0.001)$. The higher intra-individual variability of the gait kinematic parameters may indicate a lower proprioceptive control, so, it would be important enhance functional capacity, confidence, and proprioception in these patients.
\end{abstract}

Keywords: Rheumatoid arthritis; Menopause; Gait; Kinematic; Functional capacity

\section{Introduction}

Rheumatoid arthritis (RA) is a chronic inflammatory disease characterized by joint swelling, joint tenderness, and destruction of the synovial joints, factors that lead to severe disability and premature mortality [1]. Women are more predispose than men to develop rheumatoid arthritis, and in Portugal, the Reuma Census Project EpiReumaPt [2] observed a prevalence of 1.1\% in women and $0.3 \%$ in men (close to a $4: 1$ ratio). The peak incidence in females coincides with menopause when the ovarian production of sex hormones drops markedly [3].

The loss of function is a normal consequence of the rheumatoid arthritis pathogenic process. In these patients, have been found lower values of functional and physical capacities [4-9]. Moreover, rheumatoid arthritis patients also showed an increased fall risk $[10,11]$. Gait is one of the main daily activities in which falls occur [12]. Thus, measures of the gait are useful in rheumatoid arthritis patients, allowing an overall impression of its quality [13]. The few investigations that compared the gait of rheumatoid arthritis patients in relation to healthy subjects, showed changes in some temporal parameters, namely: lower speed [14-18]; shortened stride length higher cadence; prolonged double support time; and extended stance time. However, specific comparisons between healthy post-menopausal women and RA post-menopausal women were not developed. The studies [14,19] that assessed RA patients included male and/or women in the reproductive stage in their subjects selections. Even more, a comparative group of age- and sexmatched healthy subjects would have been essential to understand if any effect observed was due to the disease or due to aging or gender. However, the majority of these investigations did not use the aforementioned group.

The literature pointed to gait biomechanical parameters related with falls: a higher heel horizontal velocity at the heel strike may increase the potential for a slip-induced fall [20] and a higher minimum toe/foot clearance variability (measured by the standard deviation or interquartile range) may increase the risk of a trip-related fall [21]. However, in best of our knowledge, those gait biomechanical parameters were not studied in RA patients. According to what was aforementioned, seems to be important evaluate the effects of the disease on the gait kinematic parameters, particularly in those that are related with falls. 
Menopause may produce long-term changes in several health outcomes that may influence women's quality of life [22]. Thus, menopause was related to a decrease in the lean mass [23] and a clear deterioration in muscle performance takes place from the menopause onset [24]. On the other hand, falls are a common problem in postmenopausal women [25], and it have been found data that indicated that functional status plays an important role as a factor that increase the fall risk in postmenopausal women [26]. However, investigations that evaluated the gait changes in postmenopausal women are scarce. Therefore, if we have a sample that mixes postmenopausal and not postmenopausal women, or even men, we may be creating a bias related to the effects of menopause. Thus, the aim of this study was to compare RA postmenopausal women (the greater percentage of the RA patients) and age-matched healthy postmenopausal women (AHPW) in regard to functional capacity, gait kinematic and temporal parameters and its intra-individual variability.

\section{Methods}

\section{Subject's selection}

RA postmenopausal women $(n=20)$ were recruited in Instituto Português de Reumatologia, Lisbon, Portugal. The healthy postmenopausal women were a group of volunteers from a university of the third age (Lisbon, Portugal), selected by age and creating an age-matched group (AHPW, $\mathrm{n}=20$ ).

The reproductive and medical history of each woman was collected, and an informative written consent was obtained. The inclusion criteria were:

1. Diagnosis of post-menopausal status [22];

2. Absence of early menopause [27];

3. Inexistence of unstable heart condition, chronic obstructive pulmonary disease, or cancer;

4. Absence of prosthetics in the lower limb joints;

5. Nonparticipation in any kind of exercise program in the last 3 months;

6. Documented ability to walk unassisted for distances over seven meters (without current walking aids)

In the RA group the diagnosis of rheumatoid arthritis was made according 2010 Rheumatoid Arthritis Classification Criteria [1]. This group used stable doses of Disease-modifying antirheumatic drugs for at least 4 weeks before. The experimental procedures were performed in accordance with the Declaration of Helsinki [28] and were approved by the Ethical Committee for Health of the Instituto Português de Reumatologia.

\section{Gait biomechanical assessments}

Gait biomechanical assessments were developed at MovLab, Universidade Lusófona de Humanidades e Tecnologias, Lisbon, Portugal. The three-dimensional gait analysis used to assess the kinematic and temporal parameters was supported by the Vicon $\AA$ Motion Capture MX System (VICON Motion Systems, Oxford, UK).
This system was based on 9-camera Vicon MX (Oxford metrics, UK; $7 \times 1.3 \mathrm{MP} ; 2 \times 2.0 \mathrm{MP}$ ) connected to the MXUltranet controlling hardware. Kinetic data, necessary to determine some kinematic and temporal parameters, were collected using the Advanced Mechanical Technology Inc. (AMTI) force plate (model BP400600, AMTI, Watertown, MA, USA). This equipment was connected by a strain gage amplifier (AMTI MSA-6 MiniAmp) to the Vicon ${ }^{\circledR}$ MXControl, in order to synchronize the Vicon MXUltranet with the Vicon® Motion Capture System.

The calibration of the system was developed in accordance with the Vicon ${ }^{\circledR}$ technical specifications. The placement of the Vicon cameras was defined in function of the required volume of capture, which was defined for 2 meters before and 2 meters after the force plate. The system was prepared to record the kinematic data at $200 \mathrm{~Hz}$ and the force plate was prepared to record at $1000 \mathrm{~Hz}$, the ground reaction kinetic data.

The preparation of the subjects requires anthropometric measurements and the placement of the 41 spherical reflective markers (9.5mm diameter) on the subjects` anatomical landmarks that make up the Plug In Gait-Full Body model (Vicon Motion Systems, UK). The same investigator, that was not blind in relation to the group assignment, prepared all subjects. Anthropometric measurements were obtained using a calibrated scale (SECA 764, Hamburg, Germany) and the anthropometric suitcase Siber-Hegner.

Data acquisition was made according to the following protocol:

1. Subjects walked barefoot through a walkway that was $7 \mathrm{~m}$ long and $2 \mathrm{~m}$ wide, with a mounted force plate;

2. At the end of the walkway, the subjects turned around;

3. Subjects were asked to walk at a natural and self-selected speed; self-selected speed represents the most comfortable walking speed for subjects, which minimised either possible discomfort that could have been introduced by the predetermined speed, and minimised the induction of the subjects into a transitioning stage, that is, a stage marked by an increased variability;

4. Seven valid trials were collected for the contact of each foot on the force plate (trials were considered valid only when one foot stepped in its entirety on the force plate; this information was not given to the subjects in order to avoid changes of individual gait patterns);

5. To avoid gait performance deterioration related to fatigue, subjects rested for $2 \mathrm{~min}$ by seating on a chair every 20 trials.

\section{Gait kinematic parameters}

All trials were processed with Vicon Nexus 1.7.1 software (Oxford Metrics, UK) and using a Woltring filtering routine. The following kinematic gait parameters were analysed in the stride that began at the heel strike on the force plate: gait speed; cadence; stride length; percentage of stance phase; percentage of double support phase; percentage of the first double support phase; percentage of the first single support phase; percentage of 
the second double support phase; percentage of the second single support phase; minimum toe clearance; centre of mass anteroposterior velocity; heel antero-posterior velocity at heel strike.

Cadence (steps/min) is equal to 120 /stride period in seconds [20]. However, in this investigation the stride period was calculated from its number of frames. The vertical displacement of the marker placed on the heel, was used to know in which frame occurred the heel strike. So, the frame that showed the lower value was considered the frame where occurred the heel strike. Knowing that 1 second had 200 frames (in these data acquisition), the cadence was equal to 24000 /number of frames in the stride period. Stride length $(\mathrm{m})$ was calculated from the difference between the two heel strikes of the same foot, in relation to the values of the anteroposterior displacement of the marker placed on the heel. Gait speed (m/s) is equal to cadencexstride length/120 [20].

Stance phase is the period of time, during each stride, when the foot is in contact with the ground, expressed in percentage.
Double support phase is the period of time when both feet are in contact with the ground, expressed in percentage. The stride had four phases, namely the first double support phase, the first single support phase, the second double support phase, and the second single support phase, that can also be expressed in percentage. To calculate these percentages was necessary to find the frames in which occurred the heel strike and the toe off. The heel strike was calculated as was aforementioned. The vertical displacement of the marker placed on the toe was used to know in which frame occurred the toe off. So, the frame that showed the lower value was considered the frame where occurred the toe off. The double support phase $(\%)$ was equal to $[(b-a)+(d-c)] /(e-a)$, being a the frame where occurred the heel strike on the force plate (foot 1), b the frame where occurred the toe off of the other foot (foot 2), c the frame where occurred the heel strike of the foot $2, d$ the frame where occurred the toe off of foot 1 , and e the frame where occurred the final heel strike of foot 1 (Figure 1).

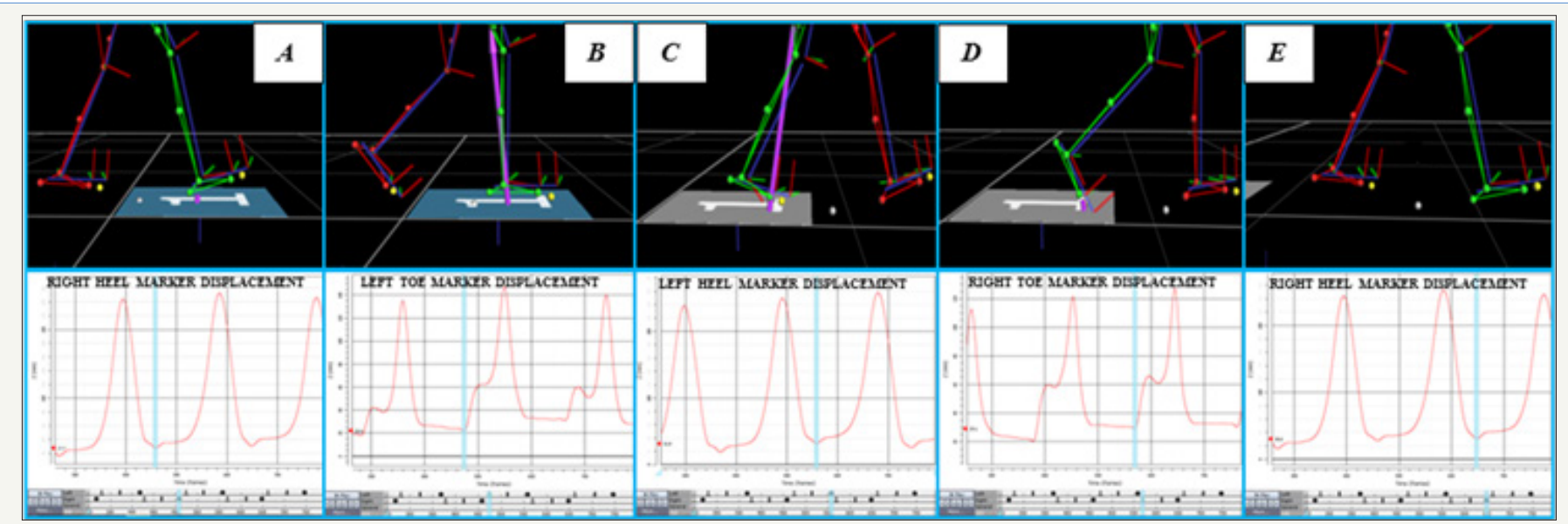

Figure 1: The frames where occurred heel strike and toe off of both feet (e.g., right heel strike on force plate).

The stance phase (\%) was equal to $(d-a) /(e-a)$; the first double support phase $(\%)$ was equal to $(b-a) /(e-a)$; the first single support phase $(\%)$ was equal to $(c-b) /(e-a)$; the second double

support phase $(\%)$ was equal to $(d-c)) /(e-a)$; the second single support phase $(\%)$ was equal to $(e-d) /(e-a)$.

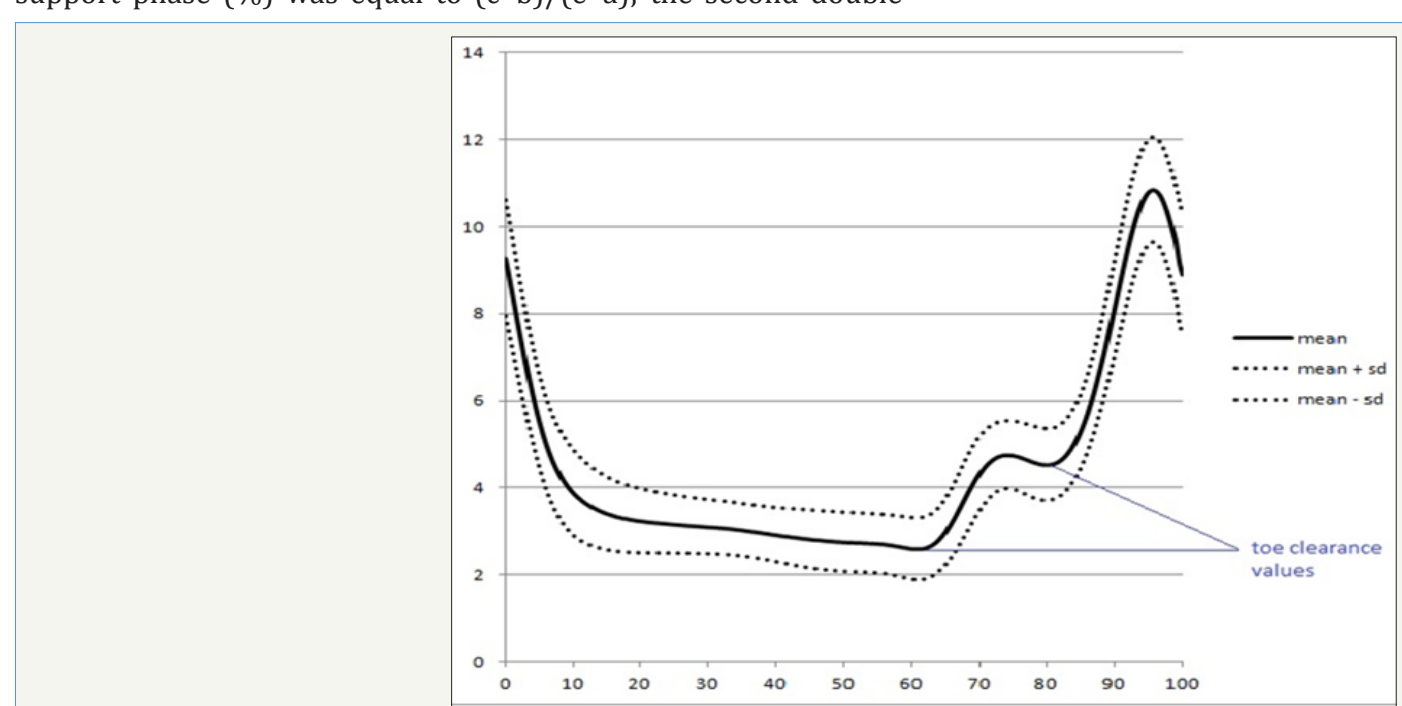

Figure 2: Mean vertical displacement of the right toe marker of the RA postmenopausal women assessed (time series normalized to $100 \%)$. 
The marker placed on the toe was used to assess the toe clearance value. During the stride were recorded two values of the vertical displacement of this marker (Figure 2): the value at toe off; and the minimum value after the instant at which the centre of mass surpasses the toe marker of the stance foot (in the sagittal plane). The difference between the two values was used to calculate the minimum toe clearance value.

The centre of mass antero-posterior velocity was recorded in three different frames, namely at the heel strike on the force plate, at the minimum toe clearance, and at toe off. The first frame where were recorded data from the force plate, was considered the frame where occurred the heel strike. The marker placed on the heel was used to assess the heel antero-posterior velocity at heel strike. The frame before heel strike on the force plate was used as reference to record the antero-posterior velocity $(\mathrm{m} / \mathrm{s})$.

\section{Disease activity assessment in RA postmenopausal women}

The Disease Activity Score-28 joints (DAS-28) was used to assess disease activity, which was calculated from the number of swollen and tender joints, the visual analogue scale for the patient assessment of global health, and the erythrocyte sedimentation rate [29]. DAS-28 is a validated index of rheumatoid arthritis activity [30]. The number of swollen and tender joints was assessed by an experienced rheumatologist, which also applied the visual analogue scale. Erythrocyte sedimentation rate was assessed in the same laboratory for all subjects. A DAS-28 score under 2.6 can be considered as disease remission [31].

\section{Functional capacity assessment}

Health Assessment Questionnaire (HAQ) [32] was used to assess the functional capacity in the two groups, which was validated for the Portuguese population [33], and has been deployed in investigations with normal aging populations and in adults and children with rheumatic diseases. Furthermore, has been widely used in clinical and investigations with rheumatoid arthritis subjects, and is a validated tool to quantify functional disability [34]. It is a 20 -item questionnaire covering activities of daily living in 8 domains: dressing, arising, eating, walking, hygiene, reach, grip, and errands and chores. There are 2 or 3 questions for each section. Scoring within each section is from 0 (without any difficulty) to 3 (unable to do) and the 8 scores of the 8 sections are summed and divided by 8 . The result is the functional disability index. This questionnaire was applied before the biomechanical assessments.

\section{Statistical analysis}

For each foot were collected 7 trials, and then calculated for all gait biomechanical parameters its intra-individual mean and its intra-individual coefficient of variation (CV). CV was used to assess intra-individual variability. These data were inserted in the Statistical Package for the Social Sciences (SPSS) for Windows (SPSS Inc., Chicago, version 17.0), to perform the statistical analysis. After these, data were analysed and given as mean and standard deviation. The independent-samples t-test was used to compare the RA postmenopausal women and the AHPW. Differences were considered statistically significant for $\mathrm{P}$ values $<0.05$. According to literature, t-tests are more powerful than nom-parametric tests [35] and even if the distribution is not normal, the significance level is almost exact for sample sizes greater than 12 [36]. Differences were considered statistically significant for $\mathrm{P}$ values $<0.05$.

\section{Results}

The results of clinical and demographic parameters are presented in Table 1. No differences were found between groups for the time of menopause, weight, height, and body mass index. Only three subjects of the RA postmenopausal women presented a DAS28 score under 2.6 and eighteen subjects of the RA postmenopausal women presented involvement of the lower limb joints. On the other hand, RA postmenopausal women group showed higher values of the HAQ score $(\mathrm{P}<0.001)$, i.e., a lower functional capacity.

Table 1: Results of the clinical, demographic, and functional capacity parameters.

\begin{tabular}{|c|c|c|c|}
\hline \multirow{2}{*}{ Variables } & RA (n=20) & AHPW (n=20) & Differences \\
\cline { 2 - 4 } & Mean (SD) & Mean (SD) & 0.984 \\
\hline Age (years) & $64.2(7.9)$ & $64.2(7.5)$ & - \\
\hline Disease duration (years) & $10.9(10.6)$ & - & - \\
\hline DAS-28 score & $3.7(1.1)$ & - & 0.635 \\
\hline Menopause duration (years) & $16.4(8.4)$ & $65.6(12.9)$ & 0.671 \\
\hline Weight (kg) & $64.0(9.9)$ & $1.54(0.06)$ & 0.3 \\
\hline Height (m) & $1.52(0.06)$ & $27.6(4.7)$ & 0.884 \\
\hline Body mass index $\left(\mathrm{kg} \bullet \mathrm{m}^{-2}\right)$ & $27.9(4.6)$ & $0.2(0.3)$ & $0.000^{*}$ \\
\hline HAQ score $(0-3)$ & $1.0(0.5)$ & . & \\
\hline
\end{tabular}

AHPW: Age-Matched Healthy Postmenopausal Women; DAS-28: Disease Activity Score-28 joints; HAQ: Health Assessment Questionnaire; RA: Rheumatoid Arthritis Postmenopausal Women; SD: Standard Deviation; * $<<0.001$

Six AHPW yielded an induced menopause (i.e., bilateral oophorectomy) whereas in the RA postmenopausal women group only three subjects showed this clinical situation. Moreover, three subjects in the RA postmenopausal women and one AHPW were using estrogen plus progestogen therapy. 
In Table 2 are presented the mean of kinematic parameters and the comparisons between groups. The RA postmenopausal women showed lower gait speed $(\mathrm{p}<0.001)$, centre of mass antero-posterior velocity $(\mathrm{p}<0.001)$, cadence $(\mathrm{p}<0.001)$, stride length $(\mathrm{p}<0.001)$, and heel antero-posterior velocity at heel strike $(\mathrm{p}<0.05)$.

Table 2: Mean \pm standard deviation of kinematic parameters of all limbs and the comparisons between groups.

\begin{tabular}{|c|c|c|c|}
\hline \multirow{2}{*}{ Kinematic Parameters } & RA $(n=40)$ & AHPW $(n=40)$ & Differences \\
\hline & Mean (SD) & Mean (SD) & P Value \\
\hline Gait speed (m/s) & $0.95(0.15)$ & $1.19(0.21)$ & $0.000^{*}$ \\
\hline Centre of mass a-p velocity $\left({ }^{1}\right)(\mathrm{m} / \mathrm{s})$ & $0.90(0.22)$ & $1.13(0.16)$ & $0.000^{*}$ \\
\hline Centre of mass a-p velocity $\left({ }^{2}\right)(\mathrm{m} / \mathrm{s})$ & $0.96(0.21)$ & $1.20(0.14)$ & $0.000^{*}$ \\
\hline Centre of mass a-p velocity $\left({ }^{3}\right)(\mathrm{m} / \mathrm{s})$ & $0.99(0.22)$ & $1.23(0.15)$ & $0.000^{*}$ \\
\hline Cadence (step/min) & $108.7(12.1)$ & $120.2(9.8)$ & $0.000^{*}$ \\
\hline Stride length $(\mathrm{m})$ & $1.04(0.14)$ & $1.19(0.09)$ & $0.000^{*}$ \\
\hline Stance phase (\%) & $61.7(2.8)$ & $60.8(2.2)$ & 0.113 \\
\hline Double support phase (\%) & $22.7(5.2)$ & $20.8(3.6)$ & 0.054 \\
\hline First double support phase (\%) & $11.6(3.1)$ & $10.4(1.9)$ & $0.039 * *$ \\
\hline First single support phase (\%) & $39.0(3.2)$ & $40.0(2.0)$ & 0.084 \\
\hline Second double support phase (\%) & $11.1(2.5)$ & $10.4(2.3)$ & 0.16 \\
\hline Second single support phase (\%) & $38.3(2.8)$ & $39.2(2.2)$ & 0.113 \\
\hline Minimum toe clearance $(\mathrm{cm})$ & $2.15(0.76)$ & $2.42(0.59)$ & 0.075 \\
\hline Heel a-p velocity (m/s) & $0.30(0.13)$ & $0.39(0.16)$ & $0.013^{* *}$ \\
\hline
\end{tabular}

AHPW: Age-Matched Healthy Postmenopausal Women; a-p: Antero-Posterior; RA: Rheumatoid Arthritis Postmenopausal Women; SD: Standard Deviation; $\left({ }^{1}\right)$ at heel strike; $\left({ }^{2}\right)$ at minimum toe clearance; $\left({ }^{3}\right)$ at toe off; ${ }^{*} \mathrm{p}<0.001 ;{ }^{* *} \mathrm{p}<0.05$.

Table 3: Intra-individual variability of gait kinematic parameters and comparisons between groups.

\begin{tabular}{|c|c|c|c|}
\hline \multirow{2}{*}{ Gait Kinematic Parameters (CV) } & $R A(n=40)$ & AHPW $(n=40)$ & Differences \\
\hline & Mean (SD) & Mean (SD) & P Value \\
\hline Gait speed & $4.6(2.8)$ & $3.0(1.5)$ & $0.001^{*}$ \\
\hline Centre of mass a-p velocity $\left({ }^{1}\right)$ & $5.1(3.0)$ & $3.6(1.2)$ & $0.003^{*}$ \\
\hline Centre of mass a-p velocity $\left({ }^{2}\right)$ & $4.6(2.9)$ & $3.4(1.4)$ & $0.017^{* *}$ \\
\hline Centre of mass a-p velocity $\left({ }^{3}\right)$ & $4.7(2.5)$ & $3.1(1.4)$ & $0.001^{*}$ \\
\hline Cadence & $3.2(1.5)$ & $2.3(0.9)$ & $0.003^{*}$ \\
\hline Stride length & $3.6(2.6)$ & $2.4(0.9)$ & $0.010^{* *}$ \\
\hline Stance phase & $2.7(1.4)$ & $2.0(1.0)$ & $0.009^{*}$ \\
\hline Double support phase & $8.3(3.1)$ & $7.4(3.2)$ & 0.21 \\
\hline First double support phase & $10.4(4.0)$ & $10.8(4.8)$ & 0.742 \\
\hline First single support phase & $4.4(2.1)$ & $3.6(1.6)$ & 0.059 \\
\hline Second double support phase & $11.6(4.5)$ & $10.7(4.6)$ & 0.376 \\
\hline Second single support phase & $4.5(2.3)$ & $3.1(1.6)$ & $0.004^{*}$ \\
\hline Minimum toe clearance & $15.6(8.3)$ & $15.7(10.3)$ & 0.99 \\
\hline Heel a-p velocity & $33.5(14.6)$ & $31.1(16.4)$ & 0.501 \\
\hline
\end{tabular}

AHPW: Age-Matched Healthy Postmenopausal Women; a-p: Antero-Posterior; CV: Intra-Individual Coefficient of Variation; RA: Rheumatoid Arthritis Postmenopausal Women; SD: Standard Deviation; $\left({ }^{1}\right)$ at heel strike; $\left({ }^{2}\right)$ at minimum toe clearance; $\left({ }^{3}\right)$ at toe off; ${ }^{*} \mathrm{p}<0.01 ;{ }^{* *} \mathrm{p}<0.05$.

The RA postmenopausal women showed (Table 3) a higher intra-individual $\mathrm{CV}$ of the gait speed, centre of mass anteroposterior velocity, cadence, stride length, and heel antero-posterior velocity at heel strike $(\mathrm{p}<0.05)$.

\section{Discussion}

Our results pointed to a lower gait speed and a lower centre of mass antero-posterior velocity in RA postmenopausal women. Previous studies [14-18] also found that rheumatoid arthritis 
patients showed a lower gait speed. However, our study was the first that exclusively compared RA postmenopausal women with AHPW, avoiding the possible bias related to the effects of menopause. The observed disease activity (showed by DAS-28 score), the involvement of the lower limbs joints in the majority of the RA postmenopausal women and the consequent reduction of functional capacity may explain the lower gait speed. These parameters also may explain the observed lower stride length in these subjects. Our results corroborated previous studies [16-18] that showed a shortened stride length in rheumatoid arthritis patients. None the less, according to literature [37-39], expectations and fears regarding the task could slow down the walking speed of the subjects. In our study we may be facing a similar situation, in other words, the RA postmenopausal women could have decreased their gait velocity to ensure a safer gait pattern. So, enhance functional capacity and confidence while walking may be needed in RA postmenopausal women, and exercise programs may be a possible strategy. Moreover, to enhance gait kinematic parameters of elderly, using exercise programs, have been reported in the literature [40-44].

A higher heel antero-posterior velocity at heel strike was found in elderly relatively to younger adults and in fallers relatively to nonfallers, suggesting that this parameter contributes for falls among older adults [45-47]. Thus, our hypothesis presupposed a higher heel velocity in RA postmenopausal women however the results showed the contrary. Lockhart \& Kimr [45] also observed a lower heel contact velocity in elderly relatively to younger adults. In this study, the participants were aware that would walk on a slippery surface, and according to the authors, the elderly` expectations and fears regarding a slippery surface could slow down their walking velocity and their heel velocity at heel strike. Thus, ours results may indicate a strategy of the RA postmenopausal women to ensure a safer gait pattern.

Two previous studies compared cadence between rheumatoid arthritis patients and healthy subjects. One study [16] did not find differences between groups and the other [18] observed a lower cadence in rheumatoid arthritis patients. Our study corroborated the results of the last one.

Previous studies found a prolonged double support time [18] and an extended stance time [16] in rheumatoid arthritis patients. Our data did not corroborated this results although seems to exist a trend to a prolonged double support phase in RA postmenopausal women, especially in the first double support phase.

Literature pointed that higher minimum toe/foot clearance variability may increase the risk of a trip-related fall [21]. However, this was the first study that assessed minimum toe clearance in rheumatoid arthritis patients and that compared RA postmenopausal women with AHPW. We found a trend to a lower minimum toe clearance in RA postmenopausal women but no difference in its variability (assessed by CV).

Our results showed a higher intra-individual variability in gait kinematic parameters of the RA postmenopausal women, namely in gait speed, centre of mass antero-posterior velocity, cadence, stride length, and heel antero-posterior velocity at heel strike. This variability may indicate a lower proprioceptive control, whereby seems to be important to improve proprioception and exercise programs can be a good possibility to improve this proprioception $[48,49]$.

\section{Conclusion}

RA postmenopausal women showed lower functional capacity and changes in gait kinematic parameters, namely in lower gait speed, centre of mass antero-posterior velocity, cadence, stride length, and heel antero-posterior velocity at heel strike. A higher intra-individual variability was also observed in gait speed, centre of mass antero-posterior velocity, cadence, stride length, and heel antero-posterior velocity at heel strike of the RA postmenopausal women. So, it would be important enhance functional capacity, confidence, and proprioception of the RA postmenopausal women, and exercise programs may be a possible strategy.

\section{References}

1. Aletaha D, Neogi T, Silman AJ, Funovits J, Felson DT, et al. (2010) 2010 rheumatoid arthritis classification criteria: an American college of rheumatology/european league against rheumatism collaborative initiative. Arthritis \& Rheumatism 62(9): 2569-2581.

2. EpiReumaPt (2014) EpiReumaPt-Estudo epidemiológico das doenças reumáticas em Portugal. Reuma Census, pp. 1-8.

3. Islander U, Jochems C, Lagerquist M, Forsblad-d'Elia H, Carlsten H (2011) Estrogens in rheumatoid arthritis; the immune system and bone. Molecular and Cellular Endocrinology 335(1): 14-29.

4. Aydoğ E, Bal A, Aydoğ S, Cakci A (2006) Evaluation of dynamic postural balance using the Biodex Stability System in rheumatoid arthritis patients. Clinical Rheumatology 25(4): 462-467.

5. Çimen O, Deviren S, Yorgancioglu Z (2001) Pulmonary function tests, aerobic capacity, respiratory muscle and endurance of patients with rheumatoid arthritis. Clinical Rheumatology 20(3): 168-173.

6. Ekdahl C, Broman G (1992) Muscle strength, endurance, and aerobic capacity in rheumatoid arthritis: a comparative study with healthy subjects. Annals of Rheumatic Disease 51(1): 35-40.

7. Hakkinen A, Hannonen P, Hakkinen K (1995) Muscle strength in healthy people and in patients suffering from recent-onset inflamatory arthritis. British Journal of Rheumatology 34(4): 355-360.

8. Madsen 0, Egsmose C (2001) Associations of isokinetic knee extensor and flexor strength with steroid use and walking ability in women with rheumatoid arthritis. Clinical Rheumatology 20(3): 207-212.

9. Meireles S, Oliveira L, Andrade M, Silva A, Natour J (2002) Isokinetic evaluation of the knee in patients with rheumatoid arthritis. Joint Bone Spine 69(6): 566-573.

10. Hayashibara M, Hagino H, Katagiri H, Okano T, Okada J, et al. (2010) Incidence and risk factors of falling in ambulatory patients with rheumatoid arthritis: a prospective 1-year study. Osteoporosis International 21(11): 1825-1833.

11. Stanmore EK, Oldham J, Skelton D, O’Neill T, Pilling M, et al. (2013b) Risk factors for falls in adults with rheumatoid arthritis: a prospective study. Arthritis Care \& Research 65(8): 1251-1258.

12. Rubenstein LZ (2006) Falls in older people: epidemiology, risk factors and strategies for prevention. Age and Ageing, 35(Suppl 2): ii37-ii41.

13. Schwartz MH, Rozumalski A (2008) The gait deviation index: a new comprehensive index of gait pathology. Gait \& Posture 28(3): 351-357. 
14. Barn R, Turner DE, Rafferty D, Sturrock RD, Woodburn J (2013) Tibialis posterior tenosynovitis and associated pes plano valgus in rheumatoid arthritis: electromyography, multisegment foot kinematics, and ultrasound features. Arthritis Care \& Research 65(4): 495-502.

15. Hakkinen A, Hannonen P, Nyman K, Lyyski T, Hakkinen K (2003) Effects of concurrent strength and endurance training in women with early or longstanding rheumatoid arthritis: comparison with healthy subjects. Arthritis \& Rheumatism 49(6): 789-797.

16. Khazzam M, Long J, Marks R, Harris G (2007) Kinematic changes of the foot and ankle in patients with systemic rheumatoid arthritis and forefoot deformity. Journal of Orthopedic Research 25(3): 319-329.

17. O'Connell P, Lohmann S, Kepple T, Stanhope S, Gerber L (1998) Forefoot deformity, pain, and mobility in rheumatoid and nonarthritic subjects. Journal of Rheumatology 25(9): 1681-1686.

18. Weiss R, Wretenberg P, Stark A, Palmblad K, Larsson P, et al. (2008) Gait pattern in rheumatoid arthritis. Gait \& Posture 28(2): 229-234.

19. Weiss R, Broström E, Stark A, Wick M, Wretenberg P (2007) Ankle/ hindfoot arthrodesis in rheumatoid arthritis improves kinematics and kinetics of the knee and hip: a prospective gait analysis study. Rheumatology 46(6): 1024-1028.

20. Winter D (1991) The Biomechanics and motor control of human gait normal, elderly and pathological ( $2^{\text {nd }}$ edn), University of Waterloo Press, Canada, pp. 87-94.

21. Barrett RS, Mills PM, Begg RK (2010) A systematic review of the effect of ageing and falls history on minimum foot clearance characteristics during level walking. Gait \& Posture 32(4): 429-435.

22. Harlow SD, Gass M, Hall JE, Lobo R, Maki P, et al. (2012) Executive summary of the stages of reproductive aging workshop +10 : addressing the unfinished agenda of staging reproductive aging. Fertility and Sterility 97(4): 843-851.

23. Sorensen M, Rosenfalck A, Hojgaard L, Ottesen B (2001) Obesity and sarcopenia after menopause are reversed by sex hormone replacement therapy. Obesity Research 9(10): 622-626.

24. Sipilä S, Taaffe D, Cheng S, Puolakka J, Toivanen J, et al. (2001) Effects of hormone replacement therapy and high-impact physical exercise on skeletal muscle in post-menopausal women: a randomized placebocontrolled study. Clinical Science 101(2): 147-157.

25. Cangussu L, Nahas-Neto J, Nahas E, Barral A, Buttros D, et al. (2012) Evaluation of postural balance in postmenopausal women and its relationship with bone mineral density: a cross sectional study. BMC Musculoskeletal Disorders 13: 2 .

26. Drozdzowska B, Wiktor K, Pluskiewicz W (2013) Functional status and prevalence of falls and fractures in population-based sample of postmenopausal women from the RAC-OST-POL Study. International Journal of Clinical Pratice 67(7): 673-681.

27. Shuster L, Rhodes D, Gostout B, Grossardt B, Rocca W (2010) Premature menopause or early menopause: Long-term health consequences. Maturitas 65(2): 161-166.

28. WMA (2013) WMA Declaration of Helsinki: ethical principles for medical research involving human subjects. Fortaleza, Brazil.

29. Smolen J, Breedveld F, Eberl G, Jones I, Leeming M, et al. (1995) Validity and reliability of the twenty-eight-joint count for the assessement of rheumatoid arthritis activity. Arthritis and Rheumatism 38(1): 38-43.

30. Prevoo M, Van't Hof M, Kuper H, Van Leeuwen M, Van de Putte L, et al. (1995) Modified disease activity scores that include twenty-eight-joint counts. Development and validation in a prospective longitudinal study of patients with rheumatoid arthritis. Arthritis \& Rheumatology 38(1): 44-48.
31. Fonseca JE, Bernardes M, Canhão H, Santos MJ, Quintal A, et al. (2011) Portuguese guidelines for the use of biological agents in rheumatoid arthritis-october 2011 update. Acta Reumatológica Portuguesa 36(4): 385-388.

32. Fries J, Spitz P, Young D (1982) The dimensions of health outcomes: the health assessment questionnaire, disability and pain scales. Journal of Rheumatology 9(5): 789-793.

33. Santos R, Reis P, Rebelo L, Dias F, Rosa C, et al. (1996) Health assessment questionnaire (versão curta): adaptação para a língua portuguesa e estudo de aplicabilidade. Acta Reumatológica Portuguesa 21(76): 15-20.

34. Piva S, Almeida G, Wasko M (2010) Association of physical function and physical activity in women with rheumatoid arthritis. Arthritis Care \& Research 62(8): 1144-1151.

35. Pereira A (2004) Guia prático de utilização do SPSS-Análise de dados para Ciências Sociais e Psicologia, Portugal, p. 166.

36. Good P, Hardin J (2003) Common errors in statistics (and how to avoid them), John Wiley \& Sons, New Jersey, USA, p. 53.

37. Brown L, Gage W, Polych M, Sleik R, Winder T (2002) Central set influence on gait. Experimental Brain Research 145(3): 286-296.

38. Lachman M, Howland J, Tennstedt S, Jette A, Assmann S, et al. (1998) Fear of falling and activity restriction: the survey of activities and fear of falling in the elderly (SAFE). Journal of Gerontology: Psychological Sciences 53B(1): 43-50.

39. Lockhart T, Woldstad J, Smith J (2003) Effects of age-related gait changes on biomechanics of slips and falls. Ergonomics, 46(12): 1136-1160.

40. Beijersbergen C, Granacher U, Vandervoort A, DeVita P, Hortobágyi $\mathrm{T}$ (2013) The biomechanical mechanism of how strength and power training improves walking speed in old adults remains unknown. Ageing Research Reviews 12(2): 618-627.

41. Gatts SK, Woollacott MH (2007) How Tai Chi improves balance: biomechanics of recovery to a walking slip in impaired seniors. Gait \& Posture 25(2): 205-214.

42. Persch L, Ugrinowitsch C, Pereira G, Rodacki A (2009) Strength training improves fall-related gait kinematics in the elderly: a randomized controlled trial. Clinical Biomechanics 24(10): 819-825.

43. Shin S, An D (2014) The effect of motor dual-task balance training on balance and gait of elderly women. Journal of Physical Therapy Science 26(3): 359-361.

44. Karst G, Hageman P, Jones T, Bunner S (1999) Reliability of foot trajectory measures within and between testing sessions. J Gerontol A Biol Sci Med Sci 54(7): M343-M347.

45. Lockhart T, Kimr S (2006) Relationship between hamstring activation rate and heel contact velocity: factors influencing age-related slipinduced falls. Gait \& Posture 24(1): 23-34.

46. Mills P, Barrett R (2001) Swing phase mechanics of healthy young and elderly men. Human Movement Science 20(4-5): 427-446.

47. Winter D, Patla A, Frank J, Walt S (1990) Biomechanical walking pattern changes in the fit and healthy elderly. Physical Therapy 70(6): 340-347.

48. Stanmore EK, Oldham J, Skelton D, O'Neill T, Pilling M, et al. (2013a) Fall incidence and outcomes of falls in a prospective study of adults with rheumatoid arthritis. Arthritis Care \& Research 65(5): 737-744.

49. Wong L, Huang W, Pope J, Haraoui B, Boire G, et al. (2015) Effect of age at menopause on disease presentation in early rheumatoid arthritis: results from the canadian early arthritis cohort. Arthritis Care \& Research 67(5): 616-623. 

(c) (i) Creative Commons Attribution 4.0

For possible submissions Click Here

Submit Article

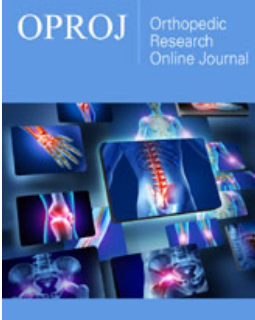

Orthopedic Research Online Journal

\section{Benefits of Publishing with us}

- High-level peer review and editorial services

- Freely accessible online immediately upon publication

- Authors retain the copyright to their work

- Licensing it under a Creative Commons license

- Visibility through different online platforms 